\title{
Research on M-Learning Combined Teaching Model of English Phonetics
}

\author{
Chen Lijuan \\ School of Foreign Languages \\ Jiujiang University \\ Jiujiang Jiangxi, China \\ 6340313@qq.com
}

\author{
Cheng Xiao \\ School of Information Science and Technology \\ Jiujiang University \\ Jiujiang Jiangxi, China \\ 410290@qq.com
}

\begin{abstract}
With the development of mobile Internet, mobile learning has become a new learning mode and is characterized by the mobility of time and space. Mobile learning is of great significance to the innovation of teaching mode in the course of professional English teaching. According to the features of English phonetics teaching, mobile learning is designed and integrated with the traditional teaching mode. New design and implementation of English phonetics teaching is combined in mobile learning procedure. It refers to constructing teaching resources, strengthening interaction and collaboration, and mastering the effect of mobile learning. The teaching mode can improve students' learning efficiency and optimize the teaching effect. It has a positive effect on the construction of teaching resources and teaching reform.
\end{abstract}

Keywords-mobile learning; fragmentation learning; teaching model; collaboration

\section{INTRODUCTION}

With the development of mobile Internet technology and the popularity of intelligent mobile terminal, mobile technology has been deep into every person's life, a mobile learning era has arrived. With a high degree of freedom, space and time, Mobile Learning style can be a good complement to the traditional learning methods by expanding teaching time and space. It will not only bring changes to the construction of education environment, resources and the teaching methods, etc. but also bring new opportunity to education informationization. [1-3].

\section{NEW MODE OF ENGLISH PHONETIC TEACHING IN MOBILE ENVIRONMENT}

In China, English phonetics is one of the compulsory courses in college English syllabus for English majors. The curriculum content generally contains three parts: the pronunciation and correct of English consonants and vowels, laws in English pronunciation variations and tone. Through studying this course, students should master English pronunciation, stress, rhythm and intonation, as well as apply learned knowledge in oral communication naturally and gracefully. The purpose of learning English phonetics is to apply language and a better language communication.
The current English Teaching mode of the curriculum of English phonetics in our school centers on classroom, takes the students as the core and the teachers' evaluation as complementary [4]. This mode reflects the characteristics of focusing study and stresses to complete the practice exercises associated with the course content within the prescribed time. In this mode, teachers ask students to preview before class and practice after class, and look forward to the improvement of students' self-learning ability. This kind of teaching mode can complete the course content request and let some students get good training in English phonetics. It is of great help to improve the students' oral communication ability.

In the process of teaching, we found that it appears many area distribution characteristics for student's practical situation of studying. About $20 \%$ of the students can get well-training in the classroom, they have a good interact with teachers and improve individual ability greatly; About $50 \%$ of the students in the classroom can keep up with the teaching content and improve personal ability through after-school practice; And about $30 \%$ of the students can only understand teaching contents in class, they have a lot difficulties in practicing independently after class, and can't improve individual ability. At the same time, as a result of the limited teaching time, teachers can only communicate with relatively small number of students, help them to train English phonetics, but most students cannot get effective help. From above, we think we should open up the second classroom outside of the classroom teaching, increase about $80 \%$ of the students' learning time, furtherly improve the quality of teaching, and achieve better teaching effect.

Mobile Learning is a kind of learning which can occur at any time and any place under the help of mobile devices. The Mobile computing devices must have the ability to effectively present Learning content and provide a two-way communication between teachers and learners in Mobile Learning. Nowadays, our country has entered into the mobile Internet era, most university students have smartphones, which provide good client environment for mobile learning. The current mobile learning can be roughly divided into three patterns: fragment learning, situational awareness learning, and classroom interactive learning based on electronic schoolbag. The manifestation of fragment learning is divergent. It has distinct characteristics and is different from "Systematic" 
learning style that is relatively professional, centralized, and continuous. The fragment learning has the characteristics of large information capacity, timeliness, modernity, and the leading edge while traditional learning has the characteristics of good foundation, system, research and application. They can work together and complement each other. Here, we chose fragment learning as the second classroom learning mode. It can make full use of fragmented time to increase the exchange of students and teachers, extend the teaching content in the classroom, spread out the classroom assessment and enable each student get the necessary guidance and training. This kind of fusion of mobile learning English phonetics teaching mode is shown in figure 1.

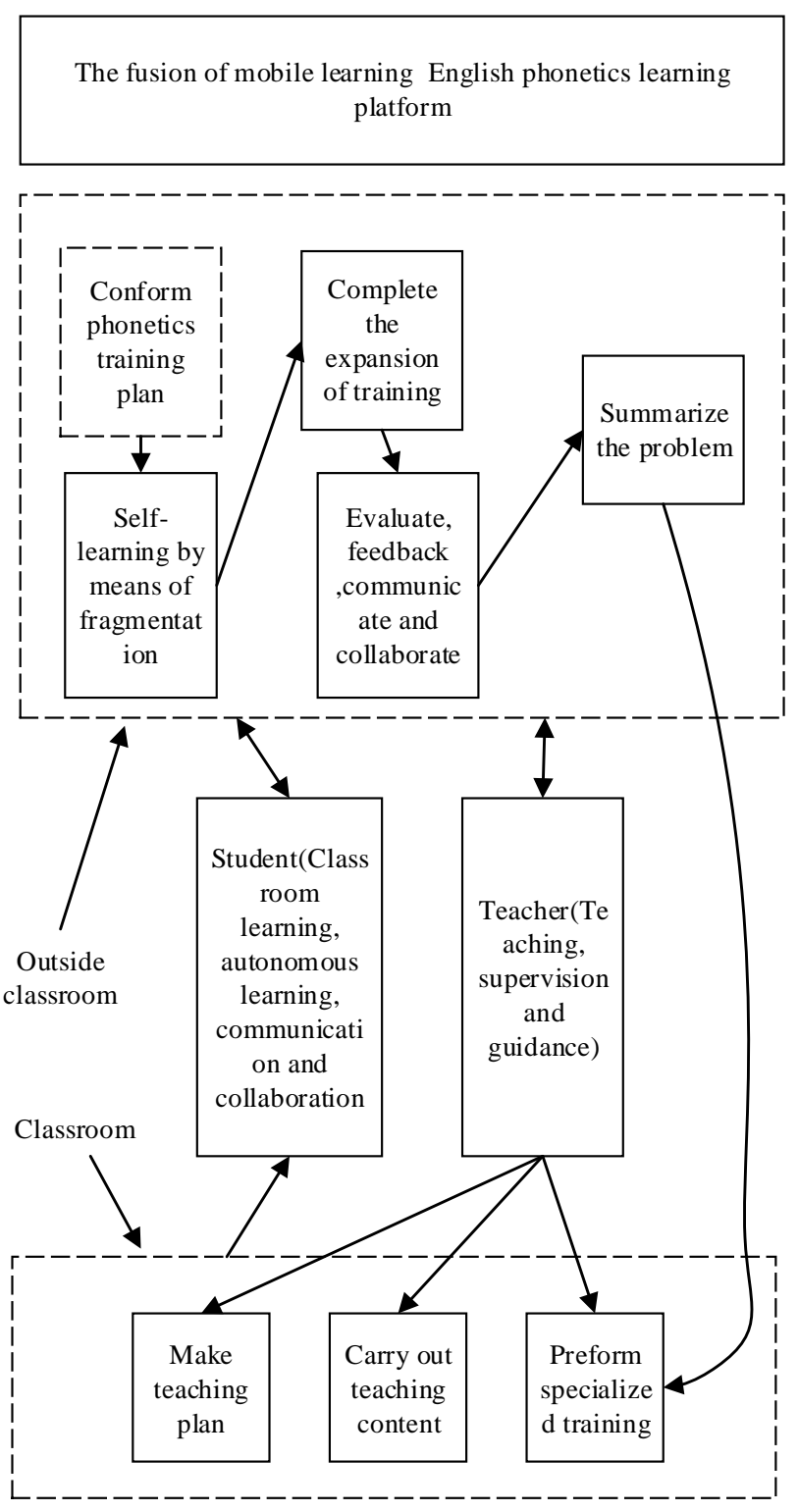

Fig. 1. M-Learning Combined Teaching Model of English Phonetics

The new teaching mode is constructed by the students and teachers. It takes a phonetic teaching platform based on Mobile Learning as carrier. On one side, students take advantage of mobile learning platform to carry out self-learning through the development of training plan, at the same time, the exchange between students can increase the interest of phonetic learning. On the other side, teachers use the mobile learning platform to provide guidance and supervise the implementation of the training program, develop a special training program through evaluation of feedback and problem summary, and thus strengthen the professional classroom teaching. In the new teaching mode, the construction of teaching platform can be divided into two steps: firstly, develop and construct the phonetic teaching platform in mobile environment, design and develop relative software; secondly, design the fragment teaching in the new mode and construct the teaching resources.

\section{ENVIRONMENTAL CONSTRUCTION OF ENGLISH PHONETIC TEACHING IN MOBILE ENVIRONMENT}

The construction of the environment of English phonetics teaching in the integrated mobile learning includes the hardware environment and software environment, which is composed of mobile wireless network, mobile terminal equipment and mobile learning system. The former two are the objective conditions, and the design and development of the mobile teaching system is the focus of the whole teaching environment. Teaching environment structure is shown in figure 2 .
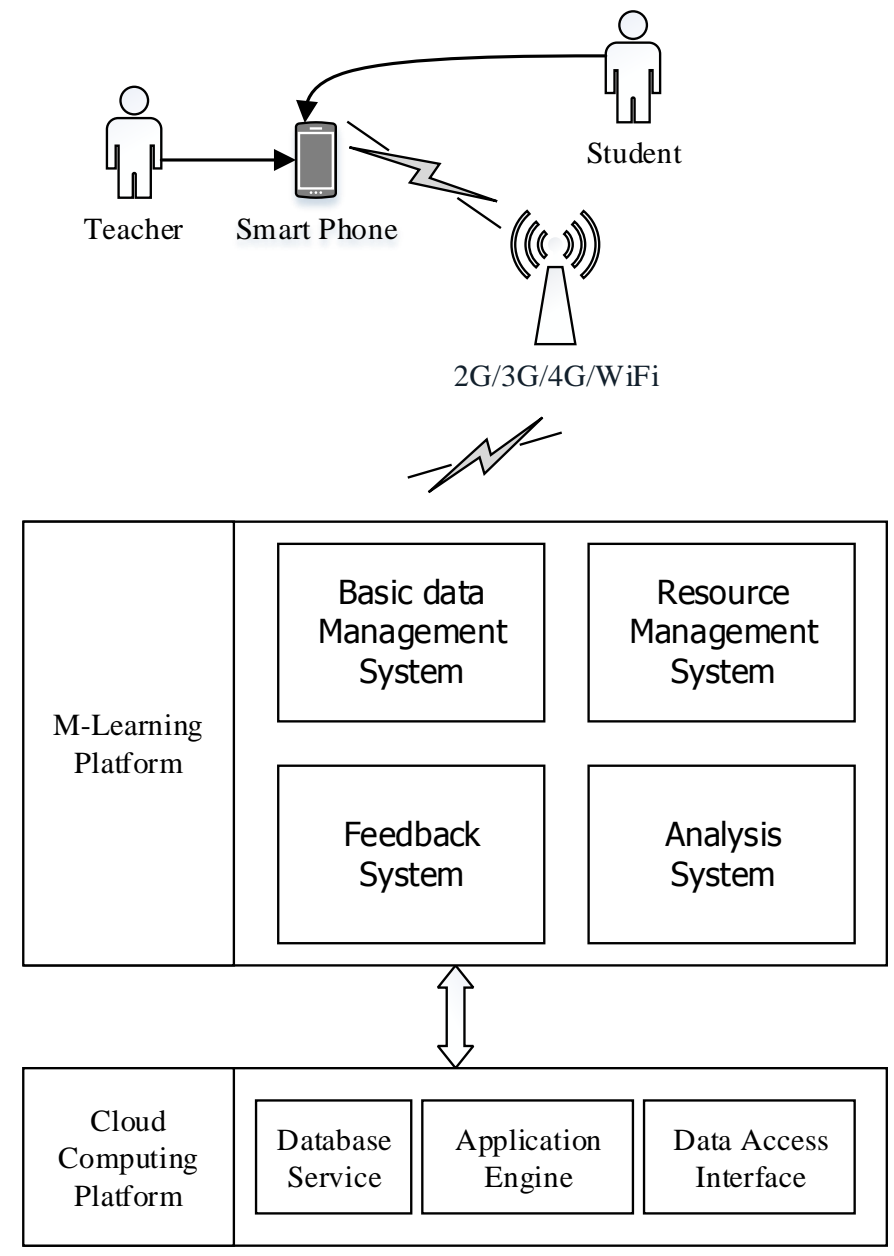

Fig. 2. Teaching environment structure 


\section{A. Mobile wireless networks.}

Mobile wireless network can make full use of $2 \mathrm{G} / 3 \mathrm{G} / 4 \mathrm{G}$ mobile communication networks, and WiFi network as well. Students can be connected to the campus wireless network which is constructed by school in the school, and can be connected to the mobile communication networks provided by mobile operators to access to mobile internet outside the school We can see that the existing mobile network has built one of the technical supports for the implementation of mobile learning in Colleges and universities, at the same time a good network environment makes all kinds of mobile learning data transmission speed faster and more rich media forms.

\section{B. Mobile terminal devices}

With the rapid development of mobile technology, mobile terminal devices has been the mainstream of intelligent terminal equipment, the processing capacity and storage capacity are greatly improved. As a new media tool, smart phone has been called the fifth media after the newspaper, radio, television and the network. The China Youth Internet behavior survey report released by China Internet Information Center shows that the smart phone has become the most important terminal among teenager internet users. The proportion of young Internet users' use mobile Internet has been more than those use desktop computers. Smart phones and tablet PCs have become an important learning tool for many students. The promotion of mobile learning based on mobile Internet and smart mobile terminal hardware conditions have been ready.

\section{The design and implementation of mobile learning system}

Mobile learning system is the core system of the environment of English phonetics teaching integrated with the mobile learning. It provides a unified access interface for both teachers and students, including the APP software based on Android and iOS system and cloud computing platform based on Web management platform and its service supports. [5, 6]

Android and iOS is currently the most widely used smartphone operating system, the APP based on the development of smartphone platform has a good usability, and both students and teachers can complete the second classroom teaching communication through mobile phone APP. Considering from the software usability, a simple design scheme is used in the APP function. App main functions include title, score, personal center three modules, for the roles of the teacher and students, respectively, are questioning and answering, evaluation and view evaluation and their respective information management and exchange. The main work flow of the mobile learning platform: (1) The teacher gives different stages of training through the mobile phone according to training plan. (2) The students are trained to record their voice and submit to the system through the mobile phone. (3) The teacher gives the evaluation by analyzing different students' pronunciation, and presents the concerned problem to evaluation feedback module. (4) The students make a targeted training based on the teacher's evaluation, and gradually improve their language ability. Mobile APP application interface is shown in figure 3 .

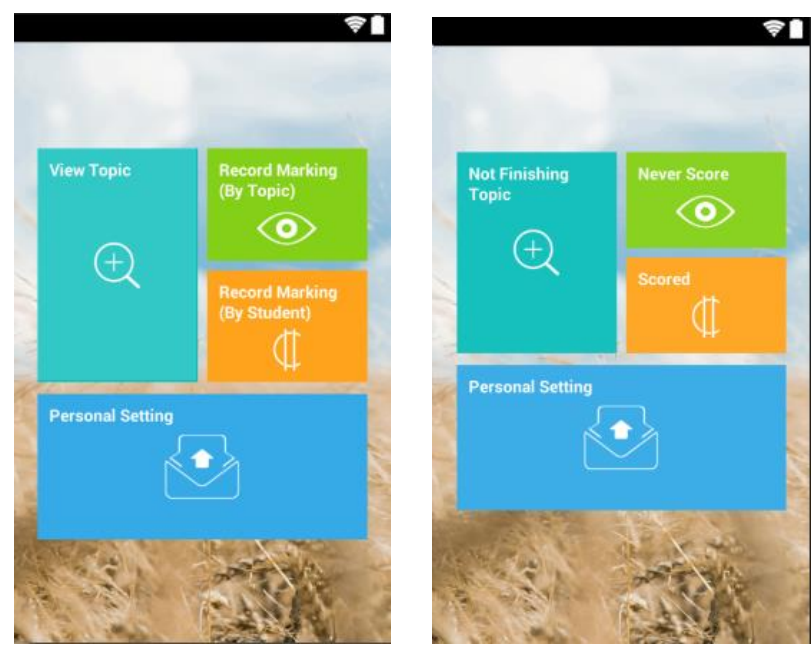

Fig. 3. APP user interface

The functions of management platform based on the web mainly includes basic data management system, voice resource management system, evaluation management system, statistical analysis management system, and provide different user roles system. The statistical analysis system mines the data through evaluating each subject in the training plan and provides data analysis report to strengthen the training of classroom teaching. The teacher can grasp the common problems of students through the analysis report provided by the system.

The cloud computing platform can choose public or private cloud to support application servers and data storage system, and provide for app unified data accessing interface. Cloud computing platform provides flexible, distributed application hosting services. It greatly reduces the hardware investment and provides better network services, and avoids the maintenance work caused by building the application service environment on its own.

\section{DESIGN AND PRACTICE OF ENGLISH PHONETICS TEACHING IN MOBILE ENVIRONMENT}

\section{A. Construction of mobile learning English phonetics resources}

Teaching resources are various materials provided for the effective development of teaching, usually including books, case, video, images, courseware, and etc., and teacher resources, teaching aids, infrastructure as well. With the development of educational technology, digital teaching resources become more and more, in the existing curriculum website, most of the resources take teaching plan as a guide and are divided by the classroom time. It emphasizes integrity and continuity, contains large amount of information, and requires learners to focus on for a longer time.

The fusion of mobile learning English phonetics teaching platform should highlight the flexibility and interactivity, emphasize the miniaturization and fragmentation of the learning contents, and the information capacity contained is 
relatively small. In mobile learning environment, learning time is scattered, and learners' attention is a short time. Therefore, the original teaching resources need to be sorted, analyzed, extended and migrated to the mobile learning platform. For the English phonetics course, it is necessary to split the long speech training content, to introduce new extracurricular content to expand and extend, and improve the effectiveness of learning resources. Regarding the length of time attention, the time of relevant video and audio resources should be controlled within 3 to 5 minutes. At the same time, it is necessary to classify the teaching resources and identify the keywords in order to analyze the results of the statistical analysis.

\section{B. Strengthen teacher-student interaction and collaborative learning model}

At present, the traditional teaching mode of university curriculum education is trying to change from "teachercentered" to "take the teachers as guide and students as main body" teaching mode. The teaching mode of integrated mobile learning is a kind of positive attempt. It breaks the mode of fixed place and fixed teaching time, promotes students to learn independently through the mobile classroom, exchange and cooperation, improves the efficiency of students learning and optimizes the teaching effect. It is helpful to strengthen training students' language communication ability.

Mobile learning system provides a communication platform, through which teachers can make a detailed evaluation of the voice information of students, and communicate with each student. The students can also evaluate and exchange with each other, the teacher can summarize and feedback through the platform. A good learning atmosphere among students is formed. We can see that the use of mobile learning system solves the problem of interaction between teachers and all students in the classroom teaching, and also solves the problem of limits communication among students due to the classroom discipline, therefore, strengthen the interaction between teachers and students.

\section{C. Master mobile learning effect}

In the classroom taking teaching as the center, learning effect is evaluated through the classroom questioning, homework, concentrated examination and so on. It has its limitations. The learning effect cannot be understood timely, and the analysis of the effect of learning requires teachers to spend more time. Thus the teaching training cannot be targeted and strengthened timely according to the learning situation.

The learning effect can also be fragmented by the fragmentation of learning, so teachers need to timely follow on learners' learning process and their master situation, and therefore master student's mobile learning effect. Based on Web management platform to provide statistical analysis, to establish a learning curve through the students answer and the results of the evaluation of teachers, to reflect the learning situation of each student in an intuitive way provide early warning tips for the slow learning process and poor learning situation. It is convenient for teachers to supervise and urge. Through intelligent analysis function of statistical analysis system, it provides teachers with the classification of students' learning problems, and provides decision-making for teachers in order to enhance the content of classroom teaching.

The construction of mobile teaching environment and teaching design and practice build a new learning model integrated classroom teaching and fragment learning. It increases interaction between teachers and students, and helps to improve classroom teaching by its statistical analysis function. Through the scientific curriculum evaluation system, the teaching quality of mobile learning is evaluated regularly, and the learning mode of the integrated mobile learning is further improved.

\section{CONCLUSION}

As a hot research area in the field of education informationization in higher education, the fusion of mobile learning English phonetics teaching mode is a beneficial exploration in the field. It will have a positive impact on the construction of teaching resources and the reform of teaching mode in the course of English major in our university.

\section{REFERENCES}

[1] Duman, Guler, Gunseli Orhon, and Nuray Gedik. Research trends in mobile assisted language learning from 2000 to 2012. ReCALL. 27.02 (2015): 197-216.

[2] Kearney, Matthew, et al. Viewing mobile learning from a pedagogical perspective. Research in learning technology, 20 (2012).

[3] Sandberg, Jacobijn, Marinus Maris, and Kaspar de Geus. Mobile English learning: An evidence-based study with fifth graders. Computers \& Education. 57.1 (2011): 1334-1347.

[4] Jianqiang, Xue. Research on construction and development of mlearning mode of College English. Experimental Technology and Management. 3 (2014): 049.

[5] Baran-Łucarz, Małgorzata, Ewa Czajka, and Walcir Cardoso. Teaching English Phonetics with a Learner Response System. Teaching and Researching the Pronunciation of English. Springer International Publishing, 2015. 35-61

[6] Jianjun, Hou, et al. M-learning Course Development and Practice Based on Tutor-Directed Online Teaching. Educational Innovation through Technology (EITT), 2014 International Conference of. IEEE, 2014. 